\title{
EVOLUÇÃO DO ENSINO DE NUTRIÇÃO NA ESCOLA DE ENFERMAGEM DA USP
}

\author{
Leda Ulson Mattos* \\ Maria Josefina Leuba Salum** \\ Hisako Shima**
}

MATTOS, L. U.; SALUM, M. J. L.; SHIMA, H. - Evolução do ensino de nutrição na Escola de Enfermagem da USP. Rev. Esc. Enf. USP, 11(1):9-18, 1977.

Os autores fazem um estudo retrospectivo das caracteristicas do ensino de Nutrição na Escola de Enfermagem da Universidade cle São Paulo desde a sua criação, em 1942.

O ensino das disciplinas da Nutrição no curso de graduação em Enfermagem foi adotado na Escola de Enfermagem da Universidade de São Paulo (USP) desde a sua criação.

A necessidade de preparar o enfermeiro para intervir adequadamente na realidade do seu campo de trabalho exige que os conhecimentos da Nutrição sejam por ele adquiridos formalmente na sua graduação, como já foi constatado (MATTOS e col., 1976).

Porém, alguns aspectos na implantação dos programas de Nutrição nas escolas de Enfermagem do Estado de São Paulo parecem não estar sendo desenvolvidos adequadamente. Assim, os estudantes sentem especialmente a falta de maior aplicação sistematizada dos conhecimentos adquiridos na área de Nutrição (MATTOS e col., não publicado).

* Prof. Livre-Docente da disciplina Nutrição e Dietética Aplicadas à Enfermagem, EEUSP.

** Auxiliar de Ensino da disciplina Nutrição e Dietética Aplicadas à Enfermagem, EEUSP. 
Pareceu-nos, dessa forma, que, para implantar as modificações necessárias no ensino da Nutrição na Escola de Enfermagem da USP, seria conveniente verificar-se como ele evoluiu desde a criação dessa escola. Dessa maneira, seria possível aproveitar as experiências anteriores, desde que parecem ter sido feitas várias modificações desde aquela data.

O presente trabalho pretende dar uma visão desse processo evolutivo através de um estudo retrospectivo e discutir as inovações que foram necessárias.

Em 31 de outubro de 1942, o Governo do Estado de São Paulo, pelo Decreto-Lei N. ${ }^{\circ} 13.040$, cria, na USP, a Escola de Enfermagem de São Paulo. O Decreto-Lei dispõe que nela será ministrado um Curso Normal de Enfermagem, com duração de 3 anos, facultado a portadores de diploma de Curso Normal ou de certificado de conclusão de Curso Ginasial. O curso incluía no primeiro ano letivo, entre outras disciplinas, as de Nutrição e Cozinha e Dietoterapia.

O Decreto-Lei N. ${ }^{\circ} 16.308$, de 16 de novembro de 1946, que "regulamenta a Escola de Enfermagem de São Paulo", dispõe no artigo $3 .^{\circ}$ que nela serão ministrados, além do curso básico, cursos de especialização.

O curso básico de Enfermagem também abrange 3 anoscalendário, de acordo com o que dita o decreto, compreendendo disciplinas separadas em 3 grupos. No terceiro grupo - Enfermagem e Ciências Afins e Ciência Médica - estão incluídas: Nutrição, Dietoterapia e Arte Culinária.

O artigo $5 .^{\circ}$ desse Decreto-Lei dispõe que o curso básico de Enfermagem divide-se em 4 períodos: pré-clínico, júnior, intermediário e senior. $O$ período pré-clínico é um estágio experimental de 6 meses desenvolvido quase que exclusivamente em salas de aula e nos laboratórios. Durante os períodos júnior, intermediário e senior, o estudante adquire prática de enfermagem em rodízio por serviços hospitalares e de saúde pública. 
O artigo $6 .^{\circ}$ desse Decreto-Lei determina que o estudante estagie durante um mês em enfermaria de Moléstias de Nutrição e Dietética, e durante 15 dias em Cozinha Geral. A Escola de Enfermagem, além das disciplinas especificadas no referido Decreto-Lei, introduziu no curriculo Dietética Infantil - ministrada paralelamente à disciplina Clínica e Enfermagem Pediátrica.

$\mathrm{Na}$ Escola de Enfermagem de São Paulo as disciplinas Nutrição e Arte Culinária eram ministradas no período pré-clínico, a disciplina Dietoterapia no período júnior e a Dietética Infantil no senior, cujas cargas horárias foram distribuídas conforme se apresentam no quadro I.

QUADRO I - Carga horária das disciplinas relacionadas à Nutrição nos anos de 1946 a 1948.

\begin{tabular}{lcc|c|l}
\hline \multirow{2}{*}{ Disciplina } & \multicolumn{3}{c|}{ N. ${ }^{\circ}$ horas/aula } & \multirow{2}{*}{ Período } \\
\cline { 2 - 5 } & Teórica & Prática & Teór./Prát. & \\
\hline Nutrição & 15 & - & - & pré-clínico \\
\hline Arte culinária & - & 15 & - & pré-clínico \\
\hline Dietoterapia & 15 & - & 15 & júnior \\
\hline Dietética Infantil & 4 & 7 & - & senior \\
\hline
\end{tabular}

Em 6 de agosto de 1949 foi promulgada a Lei 775, que dispõe sobre o ensino de Enfermagem no País, e a sua regulamentação foi feita pelo Decreto N. ${ }^{\circ} 27.426$, de 14 de novembro de 1949. O artigo 2. ${ }^{\circ}$ dessa Lei determina que a duração do curso de Enfermagem será de 36 meses, e o artigo $5 .^{\circ}$ dispõe que o ensino de Enfermagem é de nível superior, exigindo certificado de conclusão de curso secundário no ato da matrícula. Estabelece, porém, em um parágrafo único, o prazo de 7 anos para que essa exigência seja cumprida. $O$ prazó foi, no entanto, prorrogado para agosto de 1961, pela Lei 2995 de 10 de dezembro de 1956. 
Em 1949 e em 1950 a disciplina Nutrição foi ministrada no período pré-clínico, abrangendo um total de 10 horas teóricas, não sendo nesses dois anos ministrada a disciplina Arte Culinária.

No período de 1951 a 1953, houve um aumento na carga horária das disciplinas Nutrição e Arte Culinária, que passaram, assim, de 15 a 30 e de 15 a 20 horas respectivamente, sendo essas disciplinas ministradas no período pré-clínico ou no júnior. Em 1953 foi montado um laboratório para aulas práticas de nutrição. E, assim, a partir desse ano, as disciplinas relacionadas à Nutrição passaram a executar atividades práticas na Escola.

Em 10 de novembro de 1954, o Decreto N. ${ }^{\circ} 23.796-C$ aprova o Regulamento da Escola de Enfermagem, de acordo com a decisão do Conselho Universitário em sessão de 10 de agosto de 1954. O decreto dispõe no artigo $3 .^{\circ}-$ Da organização de curso de graduação: o curso de graduação, compreendendo o ensino teórico e prático e estágios em serviços hospitalares, ambulatórios e unidades sanitárias, terá a duração de 36 meses ou 160 semanas, na seguinte distribuição:

$$
\begin{aligned}
& \text { 1. }{ }^{a} \text { série }-9 \text { meses ou } 40 \text { semanas; } \\
& \text { 2. }{ }^{\mathrm{a}} \text { série }-9 \text { meses ou } 40 \text { semanas; } \\
& \text { 3. }{ }^{a} \text { série }-9 \text { meses ou } 40 \text { semanas; } \\
& \text { 4. }{ }^{a} \text { série }-9 \text { meses ou } 40 \text { semanas. }
\end{aligned}
$$

O artigo $4 .^{\circ}$ do Decreto determina a seriação das disciplinas: inclui na $1 .^{a}$ série as disciplinas Nutrição e Arte Culinária, na $2 .^{\mathrm{a}}$, a Dietoterapia, na $3 .^{a}$, a Dietética Infantil, além de estágios assim distribuídos:

1) Em Serviço de Clínica Médica: Moléstias de Nutrição e Dietoterapia - 2 semanas;

2) em outros serviços: Cozinha Geral - 2 semanas; Pediatria e Dietética Infantil -12 semanas. 
No periodo de 1954 até 1958 as disciplinas de Nutrição. foram, então, assim distribuídas:

QUADRO II - Carga horária das disciplinas relacionadas à Nutrição, nos anos de 1954 a 1958.

\begin{tabular}{l|c|c|c}
\hline \multirow{2}{*}{ Disciplina } & \multicolumn{2}{|c|}{ N. de horas } & \multirow{2}{*}{ Período } \\
\cline { 2 - 4 } & Teóricas & Práticas & \\
\hline Nutrição & 15 & - & $1 .^{\mathrm{a}}$ série \\
\hline Arte culinária & - & 30 & $1 .^{\mathrm{a}}$ série \\
\hline Dietoterapia & 15 & - & $2 .^{\mathrm{a}}$ série \\
\hline Dietética infantil & 10 & - & $2 .^{\mathrm{a}}$ série \\
\hline
\end{tabular}

Como já foi dito, o prazo estipulado pelo Decreto-Lei N. ${ }^{\circ}$ 775, de 6 de agosto de 1949, para que o ensino de Enfermagem passasse a nível superior, foi prorrogado até agosto de 1961 pela Lei 2.995 , de 10 de dezembro de 1956. A Escola de Enfermagem de São Paulo, entretanto, não esperou essa data para iniciar o curso superior, o que fez em 1958. A fim de que os candidatos de nível ginasial também tivessem oportunidade de ingressar na enfermagem ao lado do Curso Superior funcionou, um Curso Normal de Enfermagem, cujo requisito de admissão continuou a ser apenas o curso ginasial. Esses cursos, nos dois níveis, foram ministrados na Escola de Enfermagem de São Paulo de 1958 a 1963, ano em que se diplomou a última turma do Curso Normal de Enfermagem.

No quadro III discriminamos a carga horária das disciplinas da Nutrição ministradas nesse período: 
QUADRO III - Carga horária das disciplinas relacionadas à Nutrição nos anos de 1958 a 1963.

\begin{tabular}{l|c|c|l|l}
\hline \multirow{2}{*}{ Disciplina } & \multicolumn{2}{|c|}{ N. de aulas } & \multirow{2}{*}{ Período } & Curso \\
\cline { 2 - 5 } & Teóricas & Práticas & & \\
\hline Nutrição e & 10 & 20 & $1 .^{\mathrm{a}}$ série & Médio \\
Dietética & 15 & 20 & 1 . $^{\mathrm{a}}$ série & Superior \\
\hline Dietoterapia & 10 & 20 & 1 . $^{\mathrm{a}}$ série & Médio \\
& 15 & 20 & 2 . $^{\mathrm{a}}$ série & Superior \\
\hline Dietética & 10 & - & 2 . $^{\mathrm{a}}$ série & Médio \\
Infantil & 10 & - & 2 . $^{\mathrm{a}}$ série & Superior \\
\hline
\end{tabular}

Cabe chamar a atenção, aqui, que, a partir de 1958, as disciplinas Nutrição e Arte Culinária foram aglutinadas, recebendo a denominação de Nutrição e Dietética.

Em 1962 o Conselho Federal de Educação aprova o Parecer n. ${ }^{\circ} 271$ de 19 de outubro de 1962, que baixa o curriculo mínimo do Curso de Graduação em Enfermagem, o qual, não menciona as disciplinas básicas e nem as de Nutrição, todas englobadas em Fundamentos de Enfermagem. O mesmo esse Conselho faz no parecer n. ${ }^{\circ} 63$ de 6 de outubro de 1963 que cria o curso de obstetrícia modificando o parecer $n^{\circ}$ 271/61. Até 1971, a carga horária das disciplinas Nutrição e Dietoterapia não se alterou, e a de Dietética Infantil foi acrescida de 5 horas, utilizadas em aulas práticas, que constavam de preparo de mamadeiras e sopas.

Em 25 de fevereiro de 1972 o Conselho Federal de Educação aprovou o novo curriculo mínimo do curso de graduação de Enfermagem e Obstetrícia no Parecer $n .^{\circ} 163 / 72$. O currículo do curso de graduação de Enfermagem e Obstetrícia, vigente até hoje na Escola de Enfermagem da USP, baseado nesse parecer compreende 3 ciclos: 
1) pré-profissional que inclui as matérias do primeiro ciclo comum a todos os cursos da área de Saúde;

2) tronco profissional, levando à graduação do enfermeiro;

3) de habilitações, que compreende as três áreas Enfermagem Médico-Cirúrgica, Enfermagem de Saúde Pública e Enfermagem Obstétrica.

Foi então que, a partir de 1972 , as disciplinas relacionadas à Nutrição passaram, nesta Escola a ser denominadas Nutrição e Dietética Aplicadas à Enfermagem I, II e III - que correspondem, respectivamente, às disciplinas Nutrição e Dietética, Dietoterapia e Dietética Infantil. Suas características atuais são apresentadas no quadro IV.

QUADRO IV - Carga horária por disciplina da Nutrição a partir de 1972.

\begin{tabular}{l|c|c|l}
\hline \multirow{2}{*}{ Disciplina } & \multicolumn{2}{|c|}{ Crédito } & \multirow{2}{*}{ Periodo } \\
\cline { 2 - 3 } & Aula & Trabalho & \\
\hline $\begin{array}{l}\text { Nutr. e Diet. } \\
\text { aplicadas à Enf. I }\end{array}$ & 2 & 1 & $\begin{array}{l}\text { tronco } \\
\text { profissional }\end{array}$ \\
\hline $\begin{array}{l}\text { Nutr. e Diet. } \\
\text { aplicadas à Enf. II }\end{array}$ & 1 & 2 & $\begin{array}{l}\text { tronco } \\
\text { profissional }\end{array}$ \\
\hline $\begin{array}{l}\text { Nutr.e Diet. } \\
\text { aplicadas à Enf. III }\end{array}$ & 1 & - & $\begin{array}{l}\text { tronco } \\
\text { profissional }\end{array}$ \\
\hline
\end{tabular}

Obs: Crédito aula -15 horas

Crédito trabalho - 30 horas

Cabe aqui especificar as atividades escolares que correspondem ao crédito-aula e ao crédito-trabalho. Segundo o $\S 2 .^{\circ}$ do art. 99 do Regimento Geral da Universidade de São Paulo (1972), são computadas como crédito aula as seguintes atividades: aulas teóricas, seminários ou equivalente, aulas práticas ou equivalente. Esse artigo dispõe ainda que as seguintes atividades são constantes do crédito-trabalho: planeja- 
mento, execução e avaliação de pesquisa; trabalhos de campo; leituras programadas; trabalhos escritos, gráficos ou execução de peças; excursões programadas pelo Departamento.

Apesar das alterações na carga horária, pudemos verificar que o conteúdo teórico da disciplina da Nutrição, que inclui conhecimentos de Nutrição Normal, não foi alterado até a data atual. Porém, em virtude do aumento da carga horária teórica, houve possibilidade de maior aprofundamento nos conhecimentos ministrados. A partir de 1958, sob a denominação de Nutrição e Dietética, essa disciplina passou a ter 20 horas de aula teórica. No entanto, nessas 20 horas eram ministrados conhecimentos sobre arte culinária, disciplina que, como já foi dito, existiu isoladamente até essa data. Porém, a partir de 1968, a carga horária prática começou a ser utilizada para a execução e avaliação de pesquisas experimentais em animais sobre problemas relativos à nutrição. Essa atividade foi, em 1972, incorporada no crédito-trabalho.

No que toca à antiga disciplina Dietoterapia, atualmente Nutrição e Dietética Aplicadas à Enfermagem II, inclui o conhecimento dos princípios dietéticos das moléstias exigindo modificações na dieta, pudemos observar que, embora não tenha havido alterações na carga horária teórica até 1976 , o seu conteúdo prático foi significativamente alterado. Embora o número de horas computadas como aulas teóricas permanecesse o mesmo (15 horas), até 1958 estavam incluídas nessa carga horária o preparo de dietas terapêuticas (dietas hospitalares de rotina). De 1958 até 1971, foram acrescidas 20 horas para aulas práticas, que incluíam o cálculo e o preparo de dietas terapêuticas (dietas hospitalares de rotina e outras). Após a Reforma Universitária (1972), as 30 horas de crédito-trabalho passaram a ser utilizadas em trabalho de campo (planejamento, execução e avaliação da assistência nutricional do paciente) e leituras programadas, incluindo estudos de caso referentes a pacientes portadores de moléstias que exijam tratamento dietoterápico.

Quanto à disciplina Dietética Infantil, atualmente Nutrição e Dietética Aplicadas à Enfermagem III, houve, a partir de 1972, um aumento de 5 horas na sua carga horária total, que correspondem a um acréscimo na carga horária teórica. A partir de 1972, o conteúdo da disciplina se modificou, sendo incluídas aulas sobre aspectos fisiopatoló- 
gicos da desnutrição protéico-calórica e das síndromes de má absorção na criança.

Pode-se observar que as alterações verificadas na execução dos programas de ensino das disciplinas de Nutrição de São Paulo que, após a reforma universitária passou a ser denominada "Escola de Enfermagem", refletiram-se basicamente no desenvolvimento das atividades práticas, ainda que tenham sido feitas também algumas modificações no seu conteúdo teórico.

Considerando-se o ensino das disciplinas da Nutrição como um todo e baseando-se em investigação feita entre os estudantes das escolas de Enfermagem do Estado de São Paulo (MATTOS e col., não publicado), constatou-se que os estudantes sentem a necessidade de preparar algumas dietas terapêuticas. Além disso, nas avaliações finais de curso dos últimos anos, os estudantes da Escola de Enfermagem da USP manifestaram-se favoravelmente a esse tipo de atividade que já havia sido desenvolvida até o ano de 1971. E bom lembrar que de 1954 a 1958 os estudantes estagiavam no "Serviço de Clínica Médica - Moléstias da Nutrição e Dietoterapia” onde, embora não preparassem as dietas, tinham acesso à observação do seu preparo, o que nos parece fornecer subsídios adequados para maior fixação de conhecimentos.

Assim, além das atividades práticas relativas ao planejamento, execução e avaliação da assistência nutricional, parece-nos importante desenvolver atividades que abordem o cálculo e preparo de pelo menos algumas dietas terapêuticas.

A introdução de pesquisas experimentais em Nutrição e Dietética Aplicadas à Enfermagem I foi realizada com o objetivo de despertar o interesse dos estudantes pela exploração científica, além de possibilitar-lhes o entendimento dos processos nutricionais do organismo. No mesmo estudo citado anteriormente (MATTOS e col., não publicado) os estudantes das outras escolas de Enfermagem do Estado de São Paulo manifestaram-se espontaneamente sobre a necessidade de que a eles fosse dada a oportunidade de desenvolver estudos experimentais na área de Nutrição. 
Pode parecer estranho que dentro de uma Escola de Enfermagem sejam feitas pesquisas básicas de Nutrição. Mas como discute MAGALHÃES (1974) "os limites entre os vários ramos da ciência estão se diluindo, tornando praticamente impossível a separação dos campos de atuação". O mesmo autor comenta que certas profissões, "na tentativa de tornar privativo um campo geral em que várias profissões têm condições curriculares ou técnicas de atender, perturbam o ambiente científico e não trazem proveito para o desenvolvimento da ciência brasileira".

Assim, embora não seja intenção dos responsáveis pelas disciplinas da Nutrição formar especialistas nessa área, parece-nos que a formação do estudante de Enfermagem, como a de qualquer outro, deve ir além da simples aquisição de conhecimentos teórico-práticos. Preparálo para uma visão crítica dos fatos é dever de qualquer educador, e a oportunidade que é dada ao estudante de investigar cientificamente desde os bancos escolares parece-nos ter papel importante nesse processo.

MATTOS, L. U.; SALUM, M. J. L.; SHIMA, H. - Gradual development of Nutrition instruction in University of São Paulo's Nursing School. Rev. Esc. Enf. USP, 11(1):9-18, 1977.

\section{REFERENCIAS BIBLIOGRÁFICAS}

1. BRASIL, Leis, decretos, etc. Lei n. $^{\circ} 775-6$ ago. 1949. Dispõe sobre o ensino de Enfermagem no país e dá outras providências. Diário Oficial da União, Brasília, 13 ago. 1949.

2. BRASIL, Leis, decretos, etc. Decreto n. ${ }^{\circ} 27.426-14$ nov. 1949. Aprova o regulamento para os cursos de enfermagem e de auxiliar de enfermagem. Diário Oficial da União, Rio de Janeiro, 19 dez. 1949.

3. BRASIL, Leis, decretos, etc. Lei $n .^{\circ} 2.995-10 \mathrm{dez}$. 1956. Prorroga o prazo que restringe as exigências para instruir matrículas nos cursos de Enfermagem. Diário Oficial da União, Rio de Janeiro, 10 dez. 1956. 
4. MATTOS, L. U. et al. - Ensino de Nutrição nas Escolas de Enfermagem do Estado de São Paulo. São Paulo, 1976. (no prelo).

5. MAGALHÃES, L. E. Editorial: pesquisadores científicos. Ciência e Cultura. 26(1): 2, 1974.

6. BRASIL, Leis, decretos, etc. Parecer n. ${ }^{\circ}$ 163/72. Resolução n. $.^{\circ} 4-$ 25 fev. 1972. Conselho Federal de Educação. Documenta 140, julho, 1972.

7. BRASIL, Leis, decretos, etc. Decreto n. 52.326 - 16 dez. 1969. Aprova o Estatuto da Universidade de São Paulo. Estrutura Normativa da Universidade de São Paulo. São Paulo, 1969.

8. BRASIL, Leis, decretos, etc. Decreto-Lei n. ${ }^{\circ} 13.040$ - 31 out. 1942. Dispõe sobre a criação da Escola de Enfermagem. São Paulo, 1942.

9. BRASIL, Leis, decretos, etc. Decreto-Lei n. ${ }^{\circ} 16.308-16$ nov. 1946. Regulamento da Escola de Enfermagem da Universidade de São Paulo. São Paulo, 1946.

10. BRASIL, Leis, decretos, etc. Decreto n. ${ }^{\circ} 23.796-\mathrm{C}-10$ nov. 1954. Aprova o regulamento da Escola de Enfermagem de São Paulo. São Paulo, 1954.

11. BRASIL, Leis, decretos, etc. Portaria GR n. ${ }^{\circ} 1398-18$ fev. 1971. Integra na Escola de Enfermagem da Universidade de São Paulo o curso que especifica. São Paulo, 1975. 